\title{
HUBUNGAN PELAKSANAAN INISIASI MENYUSUI DINI DENGAN PEMBERIAN ASI SECARA EKSKLUSIF PADA BAYI USIA > 6 BULAN DI RUMAH BERSALIN MULIA KABUPATEN KUBU RAYA TAHUN 2019
}

\author{
Yuliana $^{1}$, Megalina Limoy ${ }^{2}$, Sherli Safitri ${ }^{3}$ \\ Akademi Kebidanan Panca Bhakti Pontianak \\ Email Korespondensi: akbidpbpontianak@gmail.com
}

\begin{abstract}
ABSTRAK
IMD merupakan awal keberhasilan dalam pemberian ASI eksklusif. Laporan status Gizi tahun 2017, bayi yang mendapatkan IMD di Indonesia 6,65\%, bayi yang mendapatkan ASI eksklusif 35,73\%. Hasil yang di dapat dari RB Mulia tahun 2019, IMD 93,5\% dan ASI eksklusif 77,4 dari 10 Bayi Baru Lahir 1 tidak IMD. Tujuan penelitian ini untuk Mengetahui adanya hubungan antara Inisiasi Menyusui Dini dengan pemberian ASI secara Eksklusif pada bayi usia > 6 bulan di Rumah Bersalin Mulia pada tahun 2019. Jenis penelitian bersifat deskriptif korelasi, untuk mengetahui hubungan antara pelaksanaan IMD dengan pemberian ASI secara eksklusif. Populasi dalam penelitian ini adalah ibu yang memiliki bayi usia > 6 bulan di Rumah Bersalin Mulia. Sebanyak 31 ibu dengan teknik purposive sampling dengan analisa data chi square. Hasil penelitian didapatkan hampir seluruh responden yaitu 29 orang responden $(93,5 \%)$ bayinya mendapatkan IMD, sedangkan sangat sedikit dari responden yang tidak mendapatkan IMD yaitu sebanyak 2 orang responden (6,5\%). Hasil tentang ASI Eksklusif diketahui bahwa sebagian besar dari responden yang memberikan ASI Eksklusif kepada bayinya adalah sebanyak 24 responden $(77,4)$, sedangkan sebagian kecil dari responden yang tidak memberikan ASI Eksklusif kepada bayinya adalah sebanyak 7 orang responden $(22,6 \%)$. Hasil analisa bivariate di peroleh $\mathrm{P}$ value 3,841 , artinya tidak ada hubungan antara pelaksanaan imd dengan pemberian asi secara eksklusif pada bayi usia $>6$ bulan di rumah bersalin mulia pada tahun 2019. Kesimpulan tidak ada hubungan antara pelaksanaan IMD dengan pemberian ASI secara eksklusif pada bayi usia > 6 bulan di Rumah Bersalin Mulia. Saran bagi Rumah Bersalin Mulia dapat meningkatkan pelaksanaan Inisiasi Menyusui Dini pada saat persalinan dan memotivas ibu agar ibu memberikan ASI eksklusif kepada bayinya.
\end{abstract}

Kata Kunci: IMD, ASI Eksklusif, Bayi Usia > 6 Bulan

\section{Pendahuluan}

Kemajuan suatu bangsa dimulai dari sumber daya manusia yang berkualitas harus dimulai dari pelaksanaan Inisiasi Menyusui Dini (IMD). World Health Organization (WHO) atau Badan Dunia pada tahun 2007 mengeluarkan protokol baru tentang "ASI Segera" sebagai tindakan life saving atau untuk menyelamatkan kehidupan bayi baru lahir (Yuhana,2008). Program Inisiasi menyusui dini dapat menyelamatkan sekurang - kurangnya 30.000 bayi di indonesia yang meninggal pada 1 jam kelahiran (Rati, 2017).

Persentase inisiasi menyusui dini $<1$ jam (IMD) pada bayi baru lahir dan ASI eksklusif di di provinsi Kalimantan Barat Indonesia tahun 2017 sebesar (61,45\%). Program Inisiasi Menyusui Dini kurang mendapat dukungan karena faktor ibu, yaitu kurangnya informasi ibu tentang pentingnya pemberian ASI, perilaku dan niat ibu untuk memberikan ASI pada anaknya.

Faktor sosial budaya seperti perubahan gaya hidup modernisasi yang cenderung tidak mau menyusui dan juga dilaporkan adanya kebiasaan masyarakat dimana para ibu menganggap kolostrum merupakan susu yang kotor yang sehingga harus dibuang. Selain itu juga gencarnya promosi susu formula dan lemahnya sanksi pada produsen susu formula

\footnotetext{
${ }^{1}$ Dosen Akademi Kebidanan Panca Bhakti Pontianak

${ }^{2}$ Dosen Akademi Kebidanan Panca Bhakti Pontianak

${ }^{3}$ Mahasiswa Akademi Kebidanan Panca Bhakti Pontianak
} 
yang merupakan faktor penghambat bagi terbentuknya kesadaran ibu untuk memberikan ASI pada anaknya (Siswono, 2007).

Berdasarkan penelitian Mashudi tahun 2012 diperoleh hasil bahwa bayi yang begitu lahir dilakukan teknik IMD pada usia 50 menit mampu menyusui lebih baik, sedangkan bayi yang tidak dilakukan teknik IMD pada usia yang sama $50 \%$ tidak dapat menyusui dengan baik. Pada usia enam bulan dan setahun, bayi yang diberikan kesempatan menyusui dini, hasilnya $59 \%$ dan 38\% yang masih disusui. Sedangkan bayi yang tidak diberi kesempatan menyusui dini pada usia yang sama tinggal 29\% dan $8 \%$ yang masih disusui (Mashudi, 2012).

Kurangnya sikap, pengertian dan pengetahuan ibu tentang manfaat ASI menjadi faktor terbesar menyebabkan ibu- ibu mudah terpengaruh dan beralih kesusu botol atau susu formula. Kendala - kendala itu biasanya kurangnya pengetahuan ibu tentang manajemen laktasi dan faktor eksternal ASI belum keluar pada hari-hari pertama sehingga ibu berfikir perlu tambah susu formula, ketidak mengertian ibu tentang kolostrum dan banyak ibu masih beranggapan bahwa ASI ibu kurang gizi, kualitasnya tidak baik, ASI tidak keluar, menghentikan pemberian ASI karena bayi atau ibu sakit, keadaan sosial ekonomi yang kurang baik sehingga ibu harus bekerja dan meninggalkan bayinya (Nancy, 2011).

Keberhasilan pelaksanaan Inisiasi Menyusu Dini yang sangat mempengaruhi keberhasilan pemberian ASI eksklusif terlihat dari hasil studi pendahuluan yang dilakukan oleh peneliti di RB Mulia yang merupakan salah satu tempat pelayanan kesehatan ibu dan anak di Kabupaten
Kubu Raya, dimana setiap bayi baru lahir yang pertolongan persalinannya di Rumah Bersalin Mulia dilakukan protokol Inisiasi Menyusui Dini, namun pada kenyataannya terjadi beberapa kegagalan.

Pelaksanaan IMD dan pemberian ASI Eksklusif terhadap 10 orang ibu yang mempunyai bayi usia $>6$ bulan, diketahui bahwa 9 orang bayi yang lahir di RB Mulia dilakukan IMD dan 1 orang tidak melakukan IMD karena kondisi bayi BBLR dengan berat 1600 gram. Pemberian ASI eksklusif pada bayi diketahui bahwa terdapat 5 orang bayi tidak diberikan ASI eksklusif dikarenakan ASI yang tidak keluar, ketakutan ibu akan bentuk payudaranya yang berubah. Adapun nutrisi yang diberikan sebagai pengganti ASI antara lain susu formula, pur buah dan nasi sejak usia bayi 4 bulan.

Hasil wawancara peneliti terhadap 5 orang ibu yang bayinya tidak diberikan ASI eksklusif mengatakan bahwa bayi sering sakit hampir setiap bulan menderita demam, batuk dan pilek, namun tidak menderita diare. Sedangkan hasil wawancara pada ibu yang bayinya diberikan ASI eksklusif diketahui bahwa kondisi bayi jarang sakit, dimana bayi demam hanya setelah imunisasi. Masih ditemukannya kegagalan 50\% pemberian ASI secara eksklusif pada bayi yang lahir di Rumah Bersalin Mulia dan telah melewati program Inisiasi Menyusu Dini saat lahir dan pendapat ibu yang menolak memberi ASI karena ketakutan akan perubahan bentuk payudara menarik peneliti untuk mengetahui "Hubungan pelaksanaan Inisiasi Menyusui Dini dengan pemberian ASI secara eksklusif pada bayi usia $>6$ bulan di Rumah Bersalin Mulia tahun 2019". 


\section{Metode}

Penelitian ini menggunakan desain penelitian deskriptif korelasi, dengan pendekatan cross sectional. Penelitian adilakukan di Rumah Bersalin Mulia dari bulan Februari sampai Juni 2019. Variabel independen dalam penelitian ini adalah pelaksanaan Inisiasi menyusui dini pada bayi segera setelah lahir. Variabel dependen adalah "Pemberian ASI eksklusif pada bayi usia $>6$ bulan. Sampel dalam penelitian ini total populasi yaitu Ibu yang melahirkan bayinya Di Rumah Bersalin Mulia pada bulan Agustus sampai September tahun 2018 yaitu sebanyak 31 orang ibu bersalin.

\section{Hasil dan Pembahasan}

Setelah dilakukan penelitian dan pengumpulan data terhadap 31 orang ibu bersalin di Rumah Bersalin mulia maka didapat hasil sebagai berikut:

Tabel 1 Karakteristik Responden di RB Mulia Tahun 2019

\begin{tabular}{|c|c|c|}
\hline \multirow{2}{*}{ Karakteristik Respoden } & \multicolumn{2}{|c|}{ Total } \\
\hline & $(\mathrm{N})$ & $(\%)$ \\
\hline \multicolumn{3}{|l|}{ Inisiasi Menyusui Dini } \\
\hline Ya & 29 & 93,5 \\
\hline Tidak & 2 & 6,5 \\
\hline \multicolumn{3}{|l|}{ ASI Eksklusif } \\
\hline Ya & 24 & 77,4 \\
\hline Tidak & 7 & 22,6 \\
\hline
\end{tabular}

Berdasarkan tabel 1 diatas, di dapatkan hasil bahwa hampir seluruh responden yaitu 29 orang responden $(93,5 \%)$ bayinya mendapatkan IMD. Menurut teori yang dikemukakan oleh Terdapat kontra indikasi pelaksanaan IMD, yakni bayi dengan Asfiksia dan Berat Badan Lahir Rendah (BBLR). Seluruh responden dalam penelitian ini (100\%) menyatakan bahwa ibu dan bayi tidak memiliki satu pun penyakit penyakit yang menjadi kontraindikasi dilakukannya IMD tersebut diatas. Roesli, 2008).

Sangat sedikit dari responden yang tidak mendapatkan IMD yaitu sebanyak 2 orang responden $(6,5 \%)$. karena 1 bayi mengalami kontraindikasi BBLR dengan berat 1600 dan asfiksia, hal ini sesuai dengan hasil penelitian yang dilakukan oleh mahmood, et al (2014), Bramson, et al (2010), yang mengatakan bahwa
IMD memiliki hubungan dengan keberhasilan ibu dalam memberikan ASI eksklusif.

Hasil penelitian ini sejalan dengan penelitian yang dilakukan oleh Meisya Jasmine Aulia (2015) dengan judul Hubungan IMD dengan pemberian ASI secara eksklusif pada bayi usia 6 - 12 bulan di Puskesmas Melati II Sleman Yogyakarta Tahun 2015, hasil menunjukkan sebanyak 23 responden $(76,7 \%)$ melakukan IMD dan 24 responden (80\%) memberikan ASI eksklusif. Pelaksanaan IMD dalam penelitian ini sesuai dengan aturan yang ada dimana Bayi Baru Lahir memenuhi indikasi untuk dilakukan IMD, dukungan dan peran tenaga kesehatan atau bidan penolong persalinan merupakan faktor penentu pelayanan IMD dan keberhasilannya, kerja sama ibu keluarga dan tenaga kesehatan diharapkan 
terjalin dengan baik sehingga ibu kooperatif dalam pelaksanaan IMD.

Tabel 1 diatas juga menunjukkan sebagian besar dari responden yang memberikan ASI eksklusif kepada bayinya adalah sebanyak 24 responden $(77,4 \%)$, sedangkan sebagian kecil dari responden yang tidak memberikan ASI eksklusif kepada bayinya adalah sebanyak 7 responden $(22,6 \%)$. Berdasarkan data tersebut menunjukkan bahwa sebagian besar responden memberikan ASI eksklusif kepada bayinya.

Menurut teori yang dikemukakan oleh Roesli, (2002) ASI eksklusif adalah bayi hanya diberi ASI saja tanpa tambahan cairan lain seperti susu formula, jeruk, madu, air putih, dan tanpa tambahan makanan padat seperti pisang, pepaya, bubur susu, biskuit, bubur nasi, dan tim. Lebih lanjut dikatakan bahwa penyusuan ASI eksklusif dianjurkan untuk jangka waktu selama empat bulan sampai enam bulan. Hasil penelitian ini sejalan dengan hasil penelitian Sari (2012) yang diperoleh nilai $\mathrm{p}=0,548$ yaitu tidak ada perbedaan pemberian ASI eksklusif antara ibu IMD dan tidak IMD. Pola pemberian ASI dalam penelitian kuantitatif meliputi pemberian kolostrum, pemberian pralekteal, pemberian ASI eksklusif, frekuensi dan lama pemberian ASI.

Peneliti menyimpulkan dari hasil penelitian bahwa ibu tidak memberikan ASI eksklusif disebabkan ibu yang tidak mengetahui manfaat ASI eksklusif dan kriteria yang dikatakan ASI eksklusif sehingga ibu cenderung memberikan makanan atau minuman tambahan kepada bayinya sebelum usia 6 bulan. Pemberian makanan ataupun minuman tambahan inilah yang memutuskan mata rantai yang dikatakan keberhasilan ASI eksklusif.

Masih ditemukan 7 orang ibu yang tidak memberikan ASI secara eksklusif pada bayinya dikarenakan 5 orang ibu mengalami gangguan ASI dan 2 orang ibu menghentikan ASI karena bekerja, hal ini sesuai dengan Teori Depkes 2009 yang menyatakan bahwa salah satu hambatan ibu menyusui secara eksklusif adalah bekerja dikarenakan kesulitan dalam mengatur waktu memompa ASI, keterbatasan dalam memilih peralatan pompa ASI dan tidak tersedianya ruangan pojok ASI. Pemberian informasi tentang cara penyimpanan asi merupakan hal yang sangat topik, dibutuhkan para ibu supaya nutrisi pada bayi tidak diganti dengan susu formula.

Tabel 2. Tabel Silang IMD Dengan ASI Eksklusif Pada Bayi Usia > 6 Bulan di RB Mulia Tahun 2019

\begin{tabular}{lcccccccc}
\hline & \multicolumn{9}{c}{ ASI Eksklusif } & & \multirow{2}{*}{ Jumlah } & \multirow{2}{*}{ P Value } \\
\cline { 2 - 7 } & IMD & $\mathrm{N}$ & $\%$ & $\mathrm{~N}$ & $\%$ & $\mathrm{~N}$ & $\%$ & \\
\cline { 2 - 7 } & 1 & 50 & 1 & 50 & 2 & 100 & \multirow{2}{*}{3,841} \\
\hline Tidak & 6 & 20,7 & 23 & 79,3 & 29 & 100 & \\
Ya & & & & & & & & \\
\hline
\end{tabular}

Berdasarkan tabel 2 diatas, maka didapatkan hasil bahwa responden yang tidak melakukan IMD serta tidak pula memberikan ASI eksklusif adalah sebanyak 1 orang 
responden (50\%), dan sebagian dari responden yang tidak melakukan IMD namun memberikan ASI eksklusif adalah sebanyak 1 (50\%). Sementara itu, sebagian besar dari responden yang mendapatkan IMD dan memberikan ASI eksklusif adalah sebanyak 23 responden $(79,3 \%)$, dan sebagian kecil dari responden yang melakukan IMD namun tidak memberikan ASI eksklusif adalah sebanyak 6 responden (20,7\%). Hasil uji silang menunjukkan $\mathrm{p}$ value yang diperoleh adalah 3,841 , artinya tidak ada hubungan antara pelaksanaan inisiasi menyusui dini dengan pemberian asi secara eksklusif pada bayi usia $>6$ bulan.

Berdasarkan hasil analisis pada lembar checklist, kegagalan responden yang mendapatkan intervensi IMD namun gagal dalam memberikan ASI eksklusif kepada bayinya, dialami oleh responden nomor 20, dikarenakan ada kontraindikasi pada bayi, yaitu bayi mengalami Berat Badan Lahir Rendah (BBLR). Responden nomor 3, 7, 23, mendapatkan IMD, tapi gagal memberikan ASI eksklusif dikarenakan sebelum berusia enam bulan, bayi pernah diberikan air putih dan koleh.

Responden nomor 10, 25, 27, bayi Mendapatkan IMD tapi tidak mendapatkan ASI secara eksklusif dikarenakan Air Susu Ibu tidak keluar dan ibu bekerja, sedangkan responden nomor 29 , bayi tidak mendapatkan IMD namun memberikan ASI secara eksklusif dikarenakan ada kontraindikasi pada bayi, pada saat proses persalinan bayi mengalami air ketuban bercampur mekonium (Asfiksia).
Hasil penelitian ini sejalan dengan penelitian yang dilakukan oleh Mashudi (2012) yang berjudul Inisiasi menyusui dini awal keberhasiIan ASI Eksklusif, menerangkan, bahwa bayi yang begitu lahir dilakukan teknik IMD pada usia 50 menit mampu menyusui lebih baik, sedangkan bayi yang tidak dilakukan teknik IMD pada usia yang sama 50\% tidak dapat menyusui dengan baik. Pada usia enam bulan dan setahun, bayi yang diberikan kesempatan menyusui dini, hasilnya 59\% dan 38\% yang masih disusui. Sedangkan bayi yang tidak diberi kesempatan menyusui dini pada usia yang sama tinggal 29\% dan $8 \%$ yang masih disusui (Mashudi, 2012).

\section{Kesimpulan}

Berdasarkan hasil yang didapatkan dari penelitian dapat disimpulkan bahwa hampir seluruh responden yaitu 29 responden $(93,5 \%)$ bayinya IMD. Sebagian besar dari responden memberikan ASI eksklusif sebanyak 24 responden $(77,4)$. Hasil analisis bivariate diperoleh nilai $\mathrm{P}$ value 3,841 , artinya tidak Ada hubungan antara pelaksanaan Inisiasi menyusui dini dengan pemberian ASI eksklusif pada bayi usia > 6 bulan. Rumah Bersalin Mulia diharapkan dapat meningkatkan pelaksanaan Inisiasi Menyusui Dini pada saat persalinan dan memotivas ibu agar ibu memberikan ASI eksklusif kepada bayinya. 


\section{Daftar Pustaka}

Arikunto, Suharsimi. 2010. Prosedur Penelitian Suatu Pendekatan Praktik. Jakarta :Rineka Cipta

Dianartiana, 2011. Perilaku Ibu Postpartum Dalam Pelaksanaan Inisiasi Menyusui Dini. http://repositpry.unhas.ac.id/493 4/1/j210070116.pdf diakses : 13 maret 2019, 09.30 WIB

Hasrimayana. 2009. Hubungan Antara Sikap Ibu Dengan Pemberian ASI Eksklusif. http://eprints.ums.ac.id/4934

/1/j210070116.pdf diakses : 15 maret 2019, 09.00 WIB

Hidayat, Aziz Alimul. 2014. Metode Penelitian Kebidanan Dan Teknik Analisis Data. Jakarta:Salemba Medika

Maryunani, 2012. Inisiasi Menyusui Dini, Asi Eksklusif Dan Manajemen Laktasi. Jakarta: TIM

Nancy. 2011. Hubungan Pengetahuan Dan Sikap Ibu Menyusui Dengan Pemberian Air Susu Ibu Secara Eksklusif. http://fkm.unsrat.ac.id/wpcontent/uploads/2012/10/winlywenas.pdf diakses : 13 maret 2019, 10.00 WIB

Rati. 2007. Hubungan Dukungan Suami Dengan Sikap Ibu Dalam Pemberian Asi Eksklusif. Diakses 10 Maret 2019, 11.00 WIB

Roesli, Utami, 2008. Inisiasi Menyusui Dini. http://repository.unimus.ac.id. Diakses 10 Maret 2019, 11.00 WIB

Sari, C.M. (2012). Perbedaan pola pemberian ASI antara ibu yang melakukan dan tidak melakukan IMD (studi di wilayah kerja puskesmas margorejo kabupaten pati). Artikel penelitian. Program Studi Ilmu Gizi, Fakultas Kedokteran. Universitas Diponogoro

Saryono, Setiawan, Ari. 2011. Metodelogi Penelitian Kebidanan Dll. DIV,SI. Dan SII. Yogyakarta
Siswono. 2007. Gambaran Tingkat Pengetahuan, Sikap, Dan Perilaku Ibu Postpartum Terhadap Pemberian Kolostrum Pada Bayi. http://repository.maranatha.edu/34 70/3/0410043_chapter1.pdf diakses : 10 maret 2019, 14.00 WIB

Sugiono. 2012. Metode Penelitian Kuantitatif, Kualitatif, Bandung: Dan R\&D

Suryaningsih, Chatarina. 2013. Pengaruh Pendidikan Kesehatan Terhadap Pengetahuan Ibu Tentang Asi Eksklusif. http://keperawatan.unsoed.ac.id/sites/ default/files/jks20130802_77-86.pdf diakses : 8 maret 2019, 13.00 WIB

Susila, dkk. 2014. Metode Penelitian Epidemiologi. Yogyakarta

Yuhana, 2008. Tingkat Pengetahuan Ibu Tentang Asi Eksklusif Dengan Praktik Pemberian Asi Eksklusif. http://digilib.unimus.ac.id/ files/ disk1/ 121/ jtptunimus-gdl-supriyatig-6044-1babi. pdf diakses : 8 maret 2019, 10.00 WIB.

Zainal, Erli. 2013. Hubungan Antara Pengetahuan Ibu, Sikap Ibu, IMD Dan Peran Bidan Dengan Pelaksanaan ASI Eksklusi 